\title{
Recognition of Farsi Letter using Hidden Markov Model
}

\author{
Sadegh Zarezade \\ Islamic Azad university \\ of Larestan, \\ Larestan,Iran
}

\author{
Abbas Akkasi \\ Islamic Azad university \\ of Larestan, \\ Larestan,Iran
}

\author{
Ayoob Maher \\ Islamic Azad university \\ of Larestan, \\ Larestan,Iran
}

\author{
Yalda Namdar \\ Islamic Azad university \\ of Larestan, \\ Larestan,Iran
}

\begin{abstract}
Letter recognition is taken from optical character recognition (OCR). Some of the applications like devices which read postal code and checks are limited to recognition of numbers and need high speed and accuracy. In current paper the combination of two powerful method i.e. hidden Markov model will be used. Other models are used only in recognition of English words in learning using online method. The accuracy of recognition is $93 \%$ for Ifn/Farsi Database.
\end{abstract}

\section{Keywords}

Recognition, Farsi letters, hidden Markov model

\section{INTRODUCTION}

Farsi Is the major language of Iran and Afghanistan and over 110 million populations including some people in Tajikistan and Pakistan speak it. Due to widespread use of this language some researchers became interested in studying problems related to recognition of Farsi handwriting [3]. Most of the work in this area devoted to recognition of Farsi texts, while this study is on the recognition of Farsi letters.[12]

Letter recognition is taken from optical character recognition (OCR). Some of the applications like devices which read postal code and checks are limited to recognition of letters and need high speed and accuracy.[12]

In Figure 1 and 2 a Farsi letter is demonstrated in written and printed versions.

\begin{tabular}{|c|c|c|c|}
\hline C & $\boldsymbol{\imath}$ & $\boldsymbol{\iota}$ \\
\hline In Isolation & $\begin{array}{c}\text { At the end of a } \\
\text { word }\end{array}$ & $\begin{array}{c}\text { In the middle of a } \\
\text { word }\end{array}$ & $\begin{array}{c}\text { At the beginning } \\
\text { of a word }\end{array}$ \\
\hline
\end{tabular}

Figure 1: A models of Farsi letter

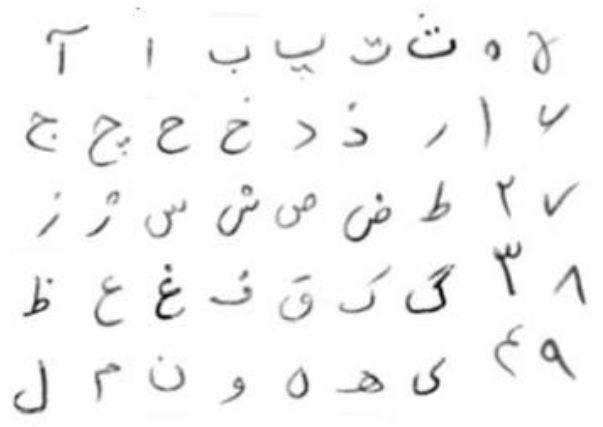

Figure 2: An models of Farsi letter

Al-Omari et al used probable neural network (PNN) for Arabic language. Their database comprised of 720 digits which could achieve $99.75 \%$ accuracy. Said et al [10] used images with the size of $16 \times 20$ for achieving that feature. They used artificial neural network (ANN) which in it hidden neurons were employed in a dynamic way. the accuracy of their method was $94 \%$. Liu et al recently propose a new criterion for recognition of Farsi handwriting. In this method they used the CENPARMI database. The error was low and they reach $84 \%$ accuracy. Drucker et al [11] worked on the textual retrieve using SVM. In this paper the method of HMM is used. Regarding our researches this method only was used for recognition of English words in a dictionary by Ahmad [3]. Nobody used this method for recognition of letters.

Our approach to OCR is a form of iterative contextual modeling, building a document-specific model by first recognizing the least ambiguous characters and then iteratively refining the model to recognize more difficult characters.

In second part of paper HMM will be discussed. In third part the model of HMM will be addressed and finally demonstrated results and a model for recognition of letters will be presented.

\section{HIDDEN MARKOV MODEL}

Hidden Markov Models (HMMs) are now widely used in

off-line handwritten recognition. Given a word image, it is first transformed into a sequence of fixed-dimension feature vectors, and then fed into a word HMM-based classifier to decide on its most probable word.

All material on each This method is based on adjustment of image templates on links of a stochastic rehidden model. According to figure 3, HMM categorizer comprised of a lot of possible situations of $\mathrm{Q}=\{\mathrm{q} 1, \Lambda, \mathrm{qk}\}$ and the possible transitions between these situations. If we suppose that there are " $k$ " situations, every of these situations have a Probability Distribution in the form of $\mathrm{p}(\mathrm{x} \mid \mathrm{qk})$. this probability is usually used by Gaussian Probability Density Function combinations as the probability of HMM distribution. One of the methods for training Gaussian parameters is the maximizing of similarities. It means that the combinations are taught for every class data rather than separating one class from the others.

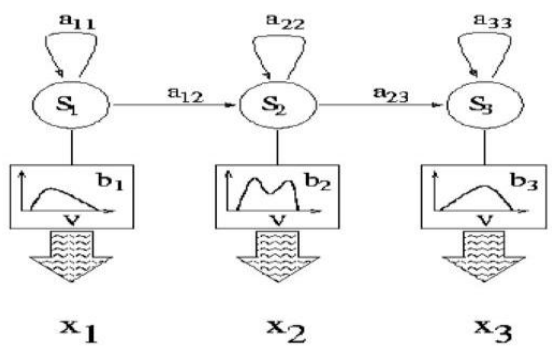

Figure 3: A Hidden Markov Model 


\section{A NEW MODEL OF HMM}

For recognition of letter with HMM were used alone. In our suggested method a more optimum method is presented. First, the extant letters in database should be segmented. A powerful method of segmentation has been used to have less calculation in processing phase.

Figure 3 shows the method of segmentation. In this method the image was segmented into 5 equal parts.

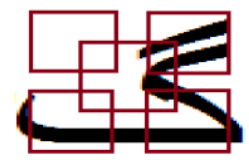

Figure 4: A new model for segmentation

In the training phase, letters have been put into classes by HMM. Some hypothesis have been received after doing preprocessing on the extant data and training with the linear HMM. The extracted hypothesis is recognizable through HMM Gaussian model.

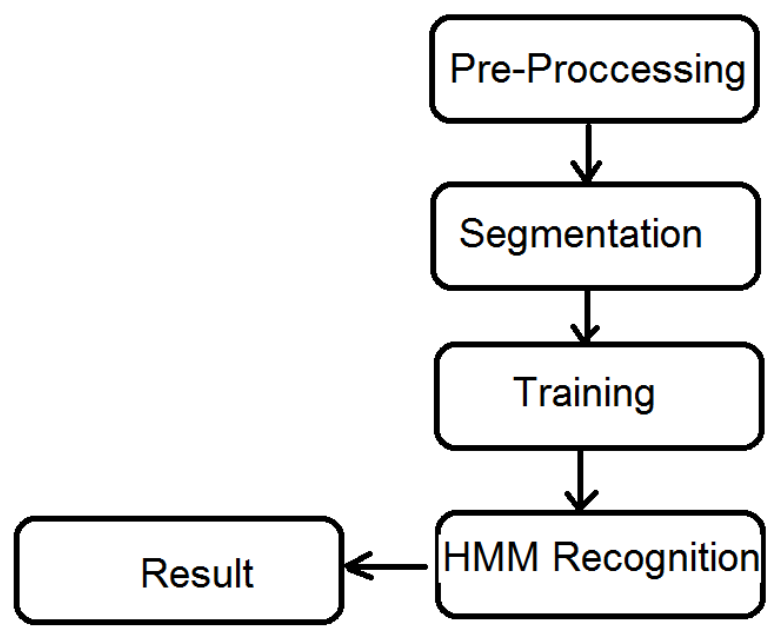

Figure 5: Model of Recognition

Figure 4 presents the procedure of implementing the algorithm. According to this figure in part 1 decent approximation has been achieved by using HMM and in part 2 the character is recognized by using HMM.

When it was supposed to use Hidden Markov Model, the calculated probabilities are used as the inputs of model and the hidden model do the recognition regarding to these probabilities.

\section{DATABASE}

In current paper two databases have been used for recognition of Farsi letter including Ifn/Farsi.

Ifn/Farsi is a Persian database for letters. The handwritten letters of this database are extracted from 100 writers with various ages and genders.. Some of the samples of this database are shown in figure 6.

\begin{tabular}{|c|}
\hline Char label (Char) \\
\hline Alif () \\
\hline Baa (ب) \\
\hline Taaa (ت) \\
\hline Thaa (ث) \\
\hline Jiim (ج) \\
\hline Haaa (c) \\
\hline Xaa (亡) \\
\hline Daal ( $(2)$ \\
\hline Thaal (i) \\
\hline Raa (J) \\
\hline Zaay (j) \\
\hline Siin (w) \\
\hline Shiin (ش) \\
\hline Saad (ص) \\
\hline Daad (ض) \\
\hline Thaaa (b) \\
\hline Taa (b) \\
\hline 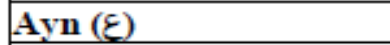 \\
\hline Ghayn $(\dot{\xi})$ \\
\hline Faa (ف) \\
\hline Gaaf (G) \\
\hline Kaaf (ك) \\
\hline Laam (J) \\
\hline Miim (ə) \\
\hline Nuun (ن) \\
\hline Haа (o) \\
\hline Waaw (g) \\
\hline Yaa (s) \\
\hline
\end{tabular}

Figure 6: Sample of Database

\section{CONCLUSION}

Following conclusions have been achieved After studying different methods with these database.

According to table 2 which is based on ifn/farsi, all the results are assessed well, but these methods has fluctuated for noise and rotation and the effectiveness declined.

In this database the result is $93 \%$ accuracy and $85.76 \%$ accuracy for times which there are rotation or change in images. Both of them are similar to SVM and are better than KNN. However, this method is better in speed of implementation and complexity in comparison with other extant methods. This is due to using the simple linear methods one-dimensional HMM (in contrast to multi-dimensional) which decrease the calculations.

Table 1: Sample of Database

\begin{tabular}{|c|c|c|c|c|}
\hline Ref & Property & Methods & $\begin{array}{c}\text { Without } \\
\text { noise (\%) }\end{array}$ & $\begin{array}{c}\text { Error } \\
(\%)\end{array}$ \\
\hline$[12]$ & Gradient & SVM & 81.42 & 18.58 \\
\hline$[12]$ & Avg.accuracy & SVM & 88.11 & 11.89 \\
\hline$[12]$ & Gradient & KNN & 83.90 & 16.1 \\
\hline$[12]$ & Avg.accuracy & KNN & 87.90 & 12.1 \\
\hline- & Gradient & HMM & 85.76 & 14.24 \\
\hline- & Avg.accuracy & HMM & 93 & 7 \\
\hline
\end{tabular}




\section{REFERENCES}

[1] C.-L.Liu and C.Y.Suen. A new benchmark on the recognition of handwritten bangla and farsi numeral characters.Pattern Recognition, In press, 2008.

[2] W.M. Pan, T.D. Bui, and C.Y. Suen : Isolated Handwritten Farsi numerals Recognition Using Sparse And Over-Complete Representations, 2009 10th International Conference on Document Analysis and Recognition

[3] Yasemin Altun and Ioannis Tsochantaridis and Thomas Hofmann: Hidden Markov Support Vector Machines, Proceedings of the Twentieth International Conference on Machine Learning (ICML-2003), Washington DC, 2003.

[4] Christopher M. Bishop: Pattern Recognition and Machine Learning, 2006 Springer Science $\square$ Business Media, LLC

[5] Usama Fayyad: A Tutorial on Support Vector Machines for Pattern Recognition, Data Mining and Knowledge Discovery, 2, 121-167 (1998)

[6] Ahmad A.R, Viard-Gaudin, C. Khalid M: Lexicon-based Word Recognition Using Support Vector Machine and Hidden Markov Model, 2009 10th International Conference on Document Analysis and Recognition

[7] F. Solimanpour, J. Sadri, C.Y. Suen, Standard databases for recognition of handwritten digits, numerical strings, legal amounts, letters and dates in Farsi language, in: Proceedings of the 10th International Workshop on
Frontiers of Handwriting Recognition, La Baule, France, 2006, pp. 3-7.

[8] Al-Omari, F., Al-Jarrah, O.: Handwritten Indian numerals recognition system using probabilistic neural networks. Adv. Eng. Inform. 18(1), 9-16 (2004)

[9] Said, F., Yacoub, R., Suen, C.: Recognition of English and Arabic numerals using a dynamic number of hidden neurons. Proc. 5th ICDAR, pp. 237-240, 1999

[10] H. Drucker, B. Shahrary, D.C. Gibbon, "Support vector machines: relevance feedback and information retrieval' ,Information Processing and Management 38, p305-323, 2002

[11] Sherif Abdleazeem and Ezzat El-Sherif: Arabic handwritten digit recognition, IJDAR (2008) 11:127-141

[12] Sameh M.Awaidah, Sabri A.Mahmoud: A multiple feature/resolution scheme to Arabic (Indian) numerals recognition using hidden Markov models, Signal Processing 89 (2009) 1176-1184

[13] H. Soltanzadeh, M. Rahmati, Recognition of Persian handwritten digits using image profiles of multiple orientations, Pattern Recognition Lett. 25 (14) (2004) $1569-1576$

[14] M. Ziaratban, K. Faez, F. Faradji, Language-based feature extraction using template-matching in Farsi/Arabic handwritten numeral recognition, in: Proceedings of the 9th International Conference on Document Analysis and Recognition, vol. 1, Curitiba, Brazil, 2007, pp. 297-301 